\title{
Behavioral Interactions Between Japanese Beetle (Coleoptera: Scarabaeidae) Grubs and an Entomopathogenic Nematode (Nematoda: Heterorhabditidae) within Turf Microcosms
}

\author{
P. C. SCHROEDER, M. G. VILLANI, ${ }^{1}$ C. S. FERGUSON, J. P. NYROP, ${ }^{1}$ aND E. J. SHIELDS \\ Department of Entomology, Cornell University, \\ Ithaca, NY 14853
}

\begin{abstract}
Environ. Entomol. 22(3): 595-600 (1993)
ABSTRACT Distribution of Japanese beetle, Popillia japonica Newman, grubs and dispersal of an entomopathogenic nematode, Heterorhabditis bacteriophora Poinar 'Oswego' strain (an isolate from New York state), were examined for 5 wk within soil-filled flats containing grass. Japanese beetle grubs uniformly dispersed to all sections of the flats not infested with $H$. bacteriophora 'Oswego' strain. In flats infested with $H$. bacteriophora 'Oswego' strain, however, greater proportions of Japanese beetle grubs were recovered in sections near the nematode release site or center sections of the flats. $H$. bacteriophora 'Oswego' strain dispersed to all sections of the flats but dispersed more rapidly within the flats infested with Japanese beetle grubs than in flats not infested with Japanese beetle grubs.
\end{abstract}

KEY WORDS Popillia japonica, Heterorhabditis bacteriophora, insect-entomopathogenic nematode interactions

The JaPanese beetle, Popillia japonica Newman, costs turf owners over $\$ 200$ million each year for control efforts and turf replacement in the northeastern United States (Ahmad et al. 1983). Insecticide applications have failed to control Japanese beetle populations adequately (Baker 1986), and public concerns about health risks posed by insecticide usage (Gaugler 1988, Villani \& Wright 1988) have encouraged turf managers to seek environmentally sound methods for controlling the Japanese beetle. Biological control tactics have been reviewed (Klein 1992) and several microbial organisms, notably the milky disease bacterium, Bacillus popilliae Dutky, and the entomopathogenic nematodes Heterorhabditis and Steinernema spp. are now being used in limited commercial efforts to control the Japanese beetle in turf (Klein 1988). The results from these efforts, however, have been variable, presumably because factors that prohibit or interfere with pathogen epizootics in the soil (e.g., edaphic environmental factors and insect-pathogen interactions) have not been clearly understood nor adequately addressed (Georgis \& Gaugler 1991).

In general, the effects of various environmental factors on entomopathogenic nematodes and on scarabs in turf have been investigated and reviewed (Klein 1992, Villani et al. 1992). How-

\footnotetext{
${ }^{1}$ Department of Entomology, New York State Agricultural Experiment Station, Geneva, NY 14456.
}

ever, behavioral responses of the Japanese beetle to nematodes and the subsequent effect of Japanese beetle behavior on nematode population dynamics have received little attention. Such interactions may inhibit or interfere with the biological control of a pest and, therefore, may contribute to frequent failures in the biological control of the Japanese beetle in turf using entomopathogenic nematodes. In this study, we investigated Japanese beetle-nematode interactions under laboratory conditions to determine if an entomopathogenic nematode, Heterorhabditis bacteriophora Poinar 'Oswego' strain, influences late-instar Japanese beetle behavior and, conversely, whether Japanese beetle grubs affect H. bacteriophora Poinar 'Oswego' strain movement and distribution in soil.

\section{Materials and Methods}

Experimental Design. On 5 February 1991, 117 flats ( 26 by 26 by $9 \mathrm{~cm}$ deep) were filled with unsterilized very fine sandy loam soil (74.1 sand, 18.0 silt, and $7.9 \%$ clay) and planted with $12 \mathrm{~g}$ of grass seeds (Agway Shady Green, Agway, Syracuse, NY). All flats were held at $24^{\circ} \mathrm{C}$ and periodically misted with water to maintain an $\approx 15 \%$ (wt:wt) soil moisture level. After the grass seeds were sown, flats were randomly assigned to one of three treatments: infested with Japanese beetle grubs only (treatment 1), infested with Japanese beetle grubs and $H$. bacteriophora Poinar 


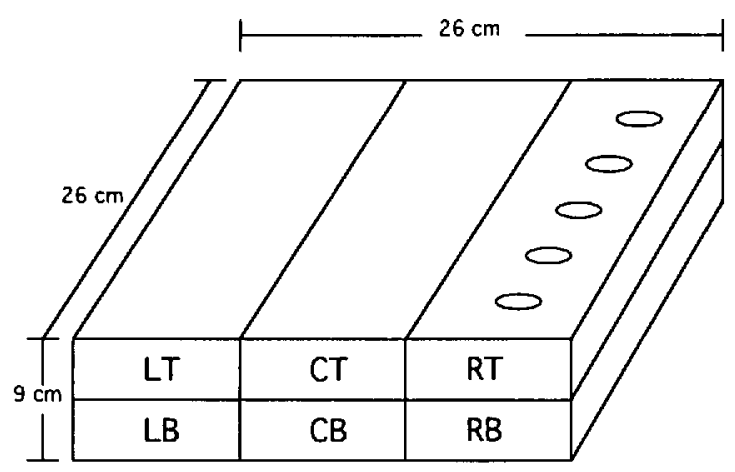

Fig. 1. Diagram of a flat showing the dimensions and pattern into which each flat was dissected: right top (RT), right bottom (RB), center top (CT), center bottorn (CB), left top (LT), and left bottom (LB) sections. Suspensions containing $H$. bacteriophora were applied to the right top section of each flat.

'Oswego' strain (treatment 2), or infested with $H$. bacteriophora Poinar 'Oswego' strain only (treatment 3). One-third (39) of the flats were assigned to each of the three treatments. Flats assigned to treatments 1 and 2 were each infested with 20 third-instar Japanese beetle grubs by placing the grubs at random locations on the soil surface 1 wk after the grass seeds were sown. Japanese beetle grubs used in these tests were collected in September and October 1990 from the turf of local golf courses (Wayne Hills Country Club, Lyons, NY, and Tuscarora Golf Club, Marcellus, $\mathrm{NY}$ ) and were stored at $10^{\circ} \mathrm{C}$ for 3 to 4 mo in soil from which they were collected. One week after the grubs were released, $5 \mathrm{ml}$ of distilled water containing $\approx 60,000$ active infective-stage nematodes, $H$. bacteriophora Poinar 'Oswego' strain, were applied to one edge (designated arbitrarily as the right side) of each flat assigned to treatment 2 or 3 . Nematodes were originally collected in September 1990 using Galleria bait traps (Bedding \& Akhurst 1975) placed in soil collected from an alfalfa field near Richland, Oswego, County, NY. Nematodes were cultured in the laboratory using greater wax moth, Galleria mellonela (L.), larvae (JaDa Bait, Antigo, WI). Each 5-ml suspension of nematodes was applied in five $1-\mathrm{ml}$ aliquots to each of five small wells spaced $\approx 4 \mathrm{~cm}$ apart and $2.5 \mathrm{~cm}$ inside the righthand edge of the flat. A similar volume of distilled water containing no nematodes was applied in the same manner to the right side of those flats assigned to treatment 1 .

At 7, 21, and $35 \mathrm{~d}$ after the nematode suspension or water was applied, the soil in one-third (13) of the flats assigned to each treatment was separated into three equally wide left, center, and right sections. Each section was further divided into two equally deep top and bottom sections (Fig. 1). Each of the six soil sections (left top, left bottom, center top, center bottom, right top, and right bottom) was sifted through a $0.64-\mathrm{cm}$ mesh wire screen and the living and nematode-infected Japanese beetle grubs were counted. Nematode infection was confirmed by inspecting each dead grub for a reddish color caused by Xenorhabdis luminescens, the mutualistic bacteria associated with $H$. bacteriophora Poinar, or by dissecting the cadaver and observing for the presence of nematodes.

Also, five 30-g samples of soil were taken from each soil section at each sample date. Each sample was placed into a $30-\mathrm{ml}$ plastic cup containing a single Galleria larva. Another Galleria larva was placed on top of the soil in each cup so that one larva was on top of the soil and one larva was on the bottom of the soil. Cups were then covered with a plastic cap and arranged on a tray. Trays were placed into a plastic bag containing a moist sponge and stored at $24^{\circ} \mathrm{C}$. After $10 \mathrm{~d}$, the Galleria larvae were examined for mortality caused by nematode infection as described above for grubs and the percentage mortality caused by nematodes ([number of Galleria infected/number of Galleria exposed] × 100) was calculated for each soil section.

Percentage mortality of Galleria caused by nematode infection is not a direct estimate of nematode density (nematodes per volume of soil), and direct methods for estimating nematode density, such as nematode flotation in sugar solutions, required levels of labor and time unavailable to our laboratory. Therefore, a separate assay was performed to estimate the relationship between the percentage mortality of Galleria caused by nematodes and the nematode density within the soil assayed. Two hundred and fifty $30-\mathrm{g}$ samples of soil were each placed into $30-\mathrm{ml}$ plastic cups each containing a single Galleria larva. The soil used in this bioassay was collected from the same source and was adjusted to the same moisture level (about $15 \%$ wt:wt) as the soil used in the experiment described above. Each cup was infested with either $0,1,5,8,10$, $16,24,32,40$, or 100 nematodes by suspending the nematodes in $0.2 \mathrm{ml}$ of water and applying the nematode suspension to the soil surface of each cup. Nematode counts of 1 to 32 were achieved by aspirating the desired number of nematodes into a micropipette. Higher counts (40 and 100) were achieved by serial dilution of nematode suspensions. Twenty-five cups were prepared and tested for each nematode density. The assay was conducted twice. After applying the nematodes, another Galleria larva was placed on top of the soil in each cup. Cups were then capped, arranged on a tray, and stored at $24^{\circ} \mathrm{C}$ in a plastic bag containing a moist sponge. After $10 \mathrm{~d}$, the Galleria larvae were examined for mortality caused by nematode infection and the percentage mortality ([number infected/number exposed] $\times 100$ ) was calculated for each nematode density. The percentage mortality of Galle- 


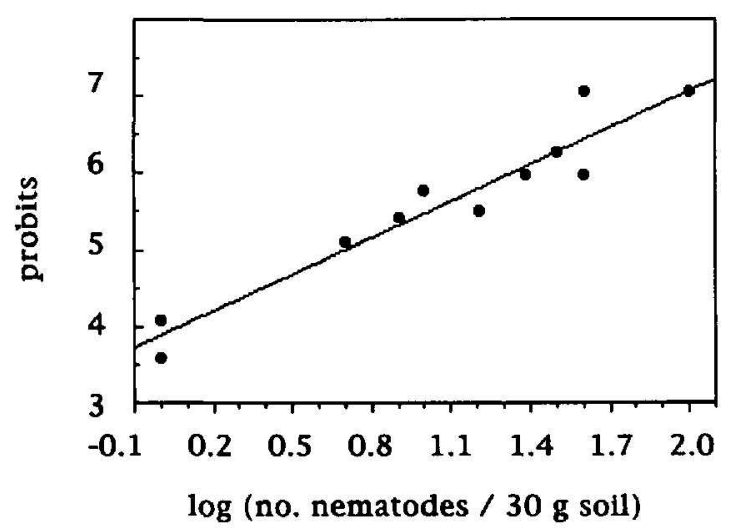

Fig. 2. Linear relationship between probits based on percentage mortality of Galleria larvae and log density of nematodes.

ria caused by nematode infection was converted to probits units (Finney 1952), then plotted against the log nematode density (Fig. 2), and the resulting regression formula (log density of nematodes per $30 \mathrm{~g}$ soil $=-2.432+0.625 *$ probits; $R^{2}=0.924 ; P=0.0001$ ) was used to convert percentage mortality to an estimate of nematode density for each soil section sampled from the nematode-infested flats.

Statistical Analysis. To allow for comparisons between sample dates, the numbers of living, nematode-infected, and total (living + nematodeinfected) grubs recovered from each flat were converted to proportions ([number of grubs within a subsection per number of grubs within a flat $\times 100$ ) before the data were analyzed statistically. Because plots of residuals against means indicated a binomial mean to variance relationship, estimates of nematode density and Japanese beetle proportions were transformed to arcsine of the square root before statistical analysis. To determine the effect of Japanese beetle grubs on nematode movement or distribution, mean nematode densities estimated from sections of flats infested with nematodes and grubs (treatment 2) were compared with mean nematode densities estimated from sections of flats infested with nematodes only (treatment 3 ). To determine the effect of nematodes on Japanese beetle movement or distribution, mean proportions of all Japanese beetle grubs (both nematodeinfested and living) recovered from sections of the flats infested with grubs only (treatment 1) were compared with mean proportions recovered from similar sections of flats infested with both grubs and nematodes (treatment 2). Estimates of nematode density and Japanese beetle grub proportions were analyzed for parallel mean responses to treatment, time (sample date), and time by treatment interaction using a multivariate analysis of variance procedure (MANOVA, Gagnon et al. 1990). A ratio of gen-

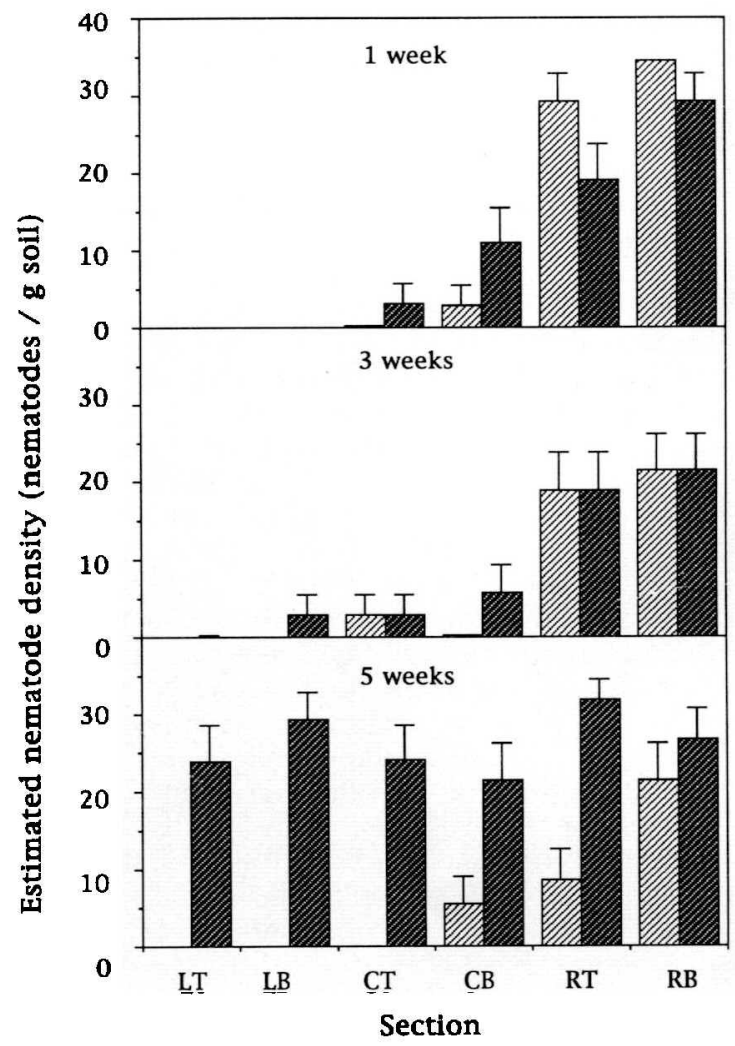

Fig. 3. Mean estimated nematode densities (number of nematodes per $g$ soil) from sections of flats infested with Japanese beetle grubs and $H$. bacteriophora (dark hashed bars) or $H$. bacteriophora only (light hashed bars) at 1,3 , and 5 wk after nematode release.

eralized variances, Wilks's lambda (Wilks 1932), was used in each test as the rejection criterion for the null hypothesis (i.e., mean responses are parallel or equal). All tests were considered significant when $P<0.05$.

\section{Results}

Effect of Japanese Beetle Grubs on Nematode Prevalence. Nematodes were recovered from all sections of the flats of both treatments on the first sample date, $1 \mathrm{wk}$ after nematode release (Fig. 3 ), although nematodes were rarely found in the left sections of the flats. Mean estimated nematode densities, however, significantly differed between treatments $(F=20.034 ; \mathrm{df}=5,68 ; P=$ $0.0001)$ and sample dates $(F=6.920 ; \mathrm{df}=10$, $136 ; P=0.0014)$. A significant treatment by sample date interaction $(F=4.439 ; \mathrm{df}=10,136 ; P=$ 0.0018 ) was also detected. Estimated nematode densities were greatest near the release site (i.e., right top and right bottom sections of the flat) in flats of both treatments. Between 3 and 5 wk after nematode release, however, estimated nematode densities in the grub-infested flats noticeably in- 
creased within the center and left sections of the flats. In the flats containing only nematodes, overall estimates of nematode density did not change between the first and last sample date, 1 and $5 \mathrm{wk}$ after nematode release, respectively.

Effect of Nematodes on Japanese Beetle Distribution. Complete recovery of all (live + dead) Japanese beetles that were released into the flats was not possible on each sample date because grubs that died because of reasons not related to nematodes were often decomposed and unrecognizable in the soil samples. Recovery of Japanese beetle grubs within individual flats ranged from 45 to $100 \%$. Although the mean percentage recovery of Japanese beetle grubs differed significantly $(F=621.474 ; \mathrm{df}=2,72 ; P=0.0082)$ between sample dates $(83,77$, and $74 \%$ for 1,3 and $5 \mathrm{wk}$ after nematode release, respectively), it did not significantly differ $(F=0.679 ; \mathrm{df}=1,72$; $P=0.4126)$ between treatments: 77 and $79 \%$ were recovered for treatment 1 (grubs only) and treatment 2 (grubs and nematodes), respectively.

Distribution of all Japanese beetle grubs within the flats differed significantly between treatments $(F=3.834 ; \mathrm{df}=5,68 ; P=0.0041)$ and sample dates $(F=3.225 ; \mathrm{df}=10,136 ; P=$ $0.0009)$. No significant treatment by sample date interaction $(F=0.781 ; \mathrm{df}=10,136 ; P=0.6466)$ was detected. In flats not infested with nematodes, live Japanese beetle grubs were recovered in relatively uniform proportions across all sections on the first two sample dates (Fig. 4). In flats infested with nematodes, however, greater proportions of all (living + nematode-infected) grubs were recovered from the bottom sections than from the top sections on the same sample dates. By the third sample date, Japanese beetle grubs were recovered in greater proportions in the bottom sections than in the top sections of the flats of both treatments.

In flats infested with nematodes, nematodeinfected grubs were found in greater proportions in the bottom sections than in the top sections on all sample dates (Fig. 5). Except for an inordinately high proportion found in the right top section of the flats, living grubs were uniformly distributed throughout the flats on the first sample date. Three weeks after nematode release, however, living grubs were primarily distributed toward the center sections of the flats. By 5 wk after nematode release, living grubs were found in greater numbers in the bottom sections than in the top sections of the flats.

\section{Discussion}

Entomopathogenic nematodes can actively disperse in soil provided soil moisture content and soil pore spaces are adequate for nematode movement (Kaya 1990). The entomopathogenic nematode used in this study, $H$. bacteriophora 'Oswego strain', was found in all sections of the

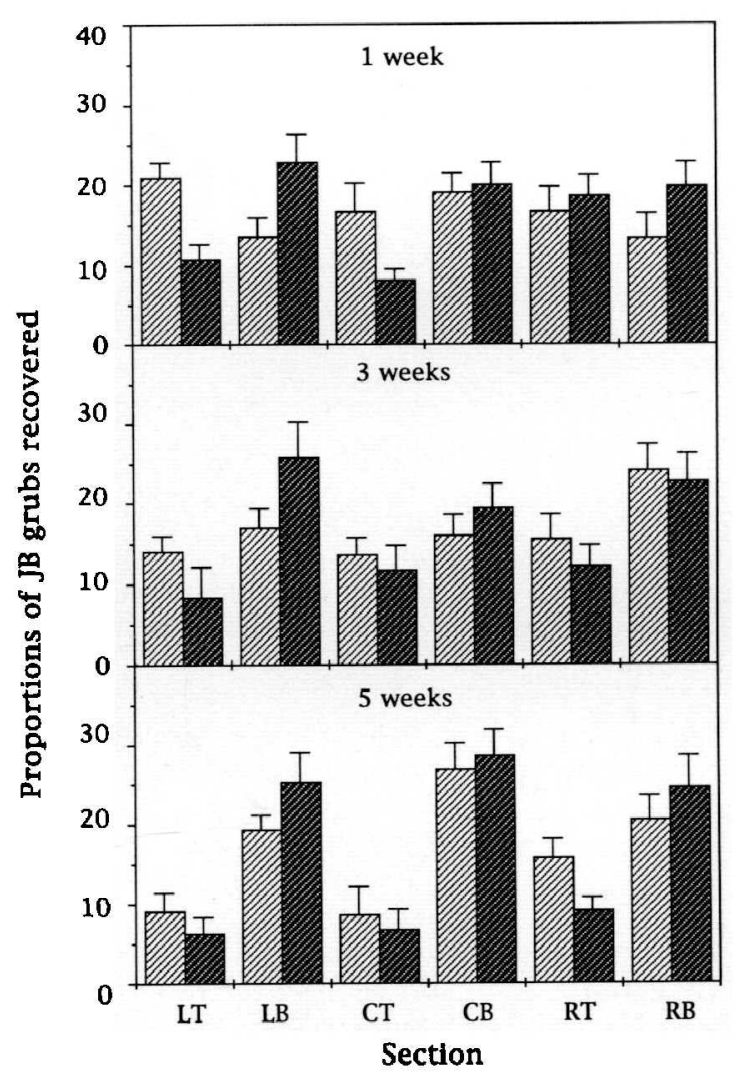

Fig. 4. Mean proportions of Japanese beetle grubs ([number recovered in section per number recovered in flat] $\times 100$ ) recovered from sections of flats infested with Japanese beetle grubs and H. bacteriophora (dark hashed bars) or Japanese beetle grubs only (light hashed bars) at 1,3 , and 5 wk after nematode release.

flats containing no grubs 1 wk after release (although nematodes were rarely recovered in the left sections of the flats). In the nematodeinfested flats containing Japanese beetle grubs, nematode-infected grubs were also recovered from all sections of the flats on all sample dates. Nematodes may have infected grubs in all sections of the flats or the grubs may have moved to different sections after becoming infected and thereby facilitated nematode movement away from the release site.

Entomopathogenic nematodes can actively migrate toward insect larvae (Schmidt \& All 1978). Dispersal of $H$. bacteriophora 'Oswego' strain in this experiment, therefore, may have been enhanced by the presence of grubs. Five weeks after the infective juveniles of $H$. bacteriophora 'Oswego' strain were released into flats containing grubs, estimated densities of the nematodes increased sharply. This abrupt increase in estimated nematode densities was probably caused by the successful reproduction (recycling) of nematodes within infected grubs.

Japanese beetle grubs within flats containing only grubs (no nematodes) were dispersed uni- 


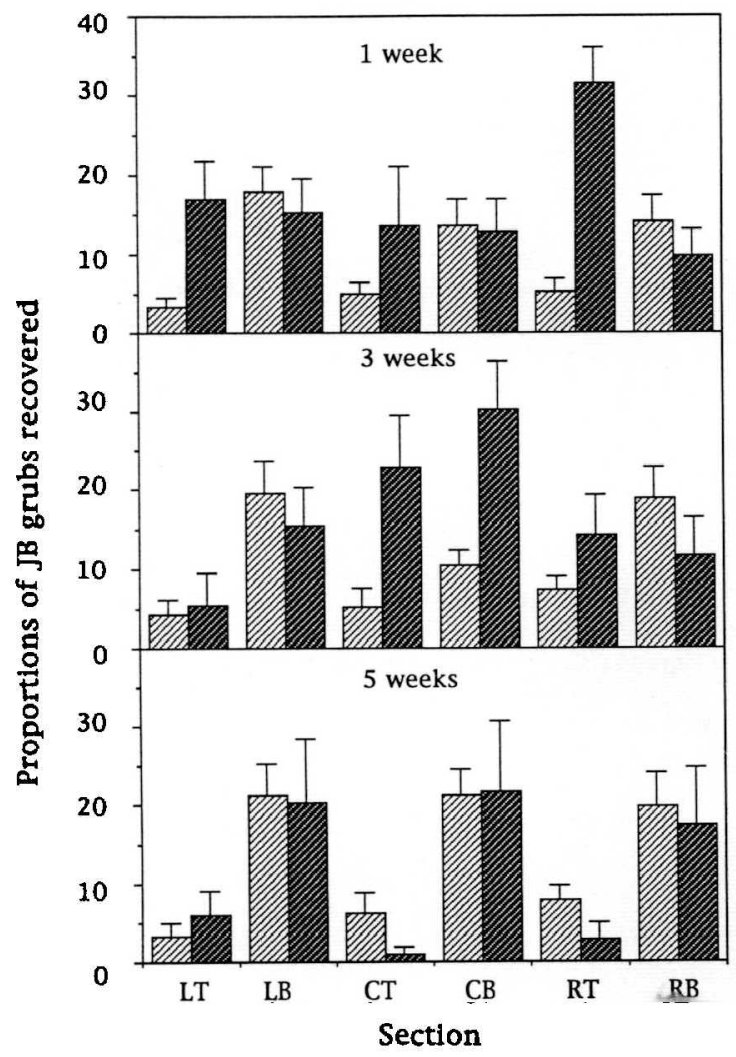

Fig. 5. Mean proportions of nematode-infected (light hashed bars) and living (dark hashed bars) Japanese beetle grubs ([number recovered in section per number recovered in flat] $\times 100$ ) recovered from sections of fats infested with Japanese beetle grubs and $H$. bacteriophora at 1,3 , and 5 wk after nematode release.

formly throughout the sections on the first and second sample dates, suggesting that the grubs had achieved a natural distribution within the flats. By the third sample date, however, grubs were recovered in greater proportions in the bottom sections than in the top sections. Because Japanese beetle grubs were approaching maturity by the third sample date, a large proportion of the grubs had apparently moved downward to pupate. In the nematode-infested flats, Japanese beetle grubs were recovered in greater proportions in the bottom than in the top sections on all sample dates. The downward movement of the grubs in the nematode-infested flats occurred, therefore, before the apparent downward movement of the mature grubs to pupate. Most of the grubs recovered from the bottom sections of the nematode-infested flats were infected with nematodes. Estimates of nematode density did not differ significantly between top and bottom sections of the flats. Therefore, differences in the number of infected grubs between top and bottom sections of the flats may not have been caused by differences in nematode densities. Soil moisture within the flats always remained within the range adequate for nematode dispersal and infection (12-16\%) and did not differ significantly $(t=1.305, \mathrm{df}=106, P>0.05)$ between the top and bottom sections of the flats. Therefore, soil moisture probably had little influence on the nematode infection rates of the grubs. The abrupt downward movement of the grubs after nematode release may have been caused by an evasive action of the healthy grubs upon encountering nematodes or a change in the normal behavior of the grub once infected by nematodes. Grubs tended to move downward in all sections despite greater estimated nematode densities on right sections of the flats. When dis. turbed, Japanese beetle grubs move downward in the soil profile (Villani \& Nyrop 1991).

Before specific information about the true nature of grub response to entomopathogenic nematodes can be answered, additional studies need to be conducted that allow for the direct observation of grub movement relative to the presence or absence of nematodes. Our study, however, illustrates that normal grub behavior may be altered because of presence or activity of the entomopathogenic nematode $\mathrm{H}$. bacteriophora ' $\mathrm{Os}$. wego' strain. An inordinate number of grubs was observed near the nematode release site $1 \mathrm{wk}$ after nematode release. The amount of water used to apply the nematodes was minimal, and no significant differences were observed between soil moistures at the release site and in adjacent sections of the flats $1 \mathrm{wk}$ after nematode release. Also, grubs were not recovered in higher numbers at the release site in flats that received water but no nematodes. Therefore, soil moisture probably did not attract grubs to the nematode release site. Grubs may have been attracted to $\mathrm{CO}_{2}$ emanating from the nematodes (Villani \& Wright 1990) or other factors associated with the nematodes.

In conclusion, the dispersal of $H$. bacteriophora 'Oswego' strain in soil depends on the presence, density, or distribution of Japanese beetle grubs. The activity or behavior of grubs can be affected, in turn, by the presence of $H$. bacteriophora 'Oswego' strain. These two interactions may in turn affect the success of $H$. bacteriophora 'Oswego' strain releases for Japanese beetle grub control in the field. Similar interactions between Japanese beetle grubs and other species and strains of entomopathogenic nematodes need to be investigated.

\section{Acknowledgments}

We thank F. Consolie, N. Consolie, and L. PrestonWilsey (Department of Entomology, New York State Agricultural Experiment Station) for technical support in the laboratory, P. Timper (Department of Plant Pathology, Cornell University) for aiding in nematode identification, and P. Davis (Department of Entomology, Cornell University) for assisting in the statistical analysis of the data. 


\section{References Cited}

Ahmad, S., H. T. Streu \& L. M. Vasvary. 1983. The Japanese beetle: a major pest of turfgrass. Am. Lawn Appl, 4: 2-10.

Baker, P. B. 1986. Responses by Japanese and oriental beetle grubs (Coleoptera: Scarabaeidae) to bendiocarb, chlorpyrifos, and isofenphos. J. Econ. Entomol. 79: 452-454.

Bedding, R. A. \& R. J. Akhurst. 1975. A simple technique for the detection of insect parasitic rhabditid nematodes in soil. Nematologica 21: 109-116.

Finney, D. J. 1952. Probit analysis. Cambridge University Press, Cambridge.

Gagnon, J., J. Roth, B. Finzer, R. Hofmann, K. Haycock, J. Simpson \& D. Feldman. 1990. SuperANOVA. Abacus Concepts, Berkeley, CA.

Gaugler, R. 1988. Ecological considerations in the biological control of soil-inhabiting insects with entomopathogenic nematodes. Agric. Ecosyst. Environ. 24: 351-360.

Georgis, R. \& R. Gaugler. 1991. Predictability in biological control using entomopathogenic nematodes. J. Econ. Entomol. 84: 713-720.

Kaya, H. K. 1990. Soil ecology, pp. 95-115. In R. Gaugler \& H. K. Haya [eds.], Entomopathogenic nematodes in biological control. CRC, Boca Raton, FL.

Klein, M. G. 1988. Pest management of soilinhabiting insects with microorganisms. Agric. Ecosyst. Environ. 24: 337-349.
1992. Use of Bacillus popillae in Japanese beetle control, pp. 179-189. In T. A. Jackson \& T. R. Glare [eds.], The use of pathogens in scarab pest management. Intercept, Andover, England.

Schmidt, J. \& J. N. All. 1978. Chemical attraction of Neoaplectana carpocapsae (Nematoda: Steinernematidae) to insect larvae. Environ. Entomol. 7: 605607.

Villani, M. G. \& J. P. Nyrop. 1991. Age-dependent movement patterns of Japanese beetle and European chafer (Coleoptera: Scarabaeidae) grubs in soil-turfgrass microcosms. Environ. Entomol. 20: 241-251.

Villani, M. G. \& R. J. Wright. 1988 . Entomopathogenic nematodes as biological control agents of European chafer and Japanese beetle (Coleoptera: Scarabaeidae). J. Econ. Entomol. 81: 484-487.

1990. Environmental influences on soil macroarthropod behavior in agricultural systems. Annu. Rev. Entomol. 35: 249-269.

Villani, M. G., S. R. Krueger \& J. P. Nyrop. 1992. A case study of the impact of the soil environment on insect/pathogen interactions: scarabs in turfgrass, pp. 111-126. In T. A. Jackson \& T. R. Glare [eds.], The use of pathogens in scarab pest management. Intercept Books, Andover, England.

Wilks, S. S. 1932. Certain generalizations in the analysis of variance. Biometrika 24: 471-494.

Received for publication 22 September 1992; accepted 26 January 1993. 